\title{
Two alternate mechanisms contribute to the persistence of interdependent lineages in Pogonomyrmex harvester ants
}

\author{
TANJA SCHWANDER, ${ }^{*}$ LAURENT KELLER* and SARA HELMS CAHAN† \\ *Department of Ecology and Evolution, University of Lausanne, CH-1015 Lausanne, Switzerland, +Department of Biology, University \\ of Vermont, Burlington, VT 05405, USA
}

\begin{abstract}
Some populations of Pogonomyrmex harvester ants comprise pairs of highly differentiated lineages with queens mating at random with several males of their own and of the alternate lineage. These queens produce two types of diploid offspring, those fertilized by males of the queens' lineage which develop into new queens and those fertilized by males of the other lineage which mostly develop into functionally sterile workers. This unusual mode of genetic caste determination has been found in 26 populations and a total of four lineage pairs $\left(F_{1}-F_{2}, G_{1}-G_{2}, H_{1}-H_{2}\right.$ and $\left.J_{1}-J_{2}\right)$ have been described in these populations. Despite the fact that a few interlineage queens are produced, previous studies revealed that there is a complete lack of genetic introgression between lineages. Here we quantify the proportion of interlineage queens produced in each of the four lineage pairs and determine the fate of these queens. In the $\mathrm{F}_{1}-\mathrm{F}_{2}, \mathrm{G}_{1}-\mathrm{G}_{2}$ and $\mathrm{H}_{1}-\mathrm{H}_{2}$ lineage pairs, interlineage queens were produced by a minority of colonies. These colonies exclusively produced interlineage queens and workers, suggesting that interlineage eggs can develop into queens in these three pairs of lineages in the absence of competition with pure-lineage brood. An analysis of three key stages of the colony life cycle revealed that colonies headed by interlineage queens failed to grow sufficiently to produce reproductive individuals. In laboratory comparisons, interlineage queens produced fewer viable eggs, with the effect that they raised fewer workers and lost more weight per worker produced than pure-lineage queens. In the $\mathrm{J}_{1}-\mathrm{J}_{2}$ lineage pair, we did not find a single interlineage queen, raising the possibility that interlineage eggs have completely lost the ability to develop into queens in this lineage pair. Hence, two distinct mechanisms seem to account for the complete lack of between-lineage gene flow in the $F_{1}-F_{2}, G_{1}-G_{2}, H_{1}-H_{2}$ and $J_{1}-J_{2}$ lineage pairs.
\end{abstract}

Keywords: colony founding success, genetic caste determination, hybrid, Pogonomyrmex lineages

Received 23 February 2007; revision accepted 27 April 2007

\section{Introduction}

Hybrid zones occur when genetically distinct groups of individuals meet and mate, resulting in at least some offspring of mixed ancestry. Several studies have revealed that hybridization can provide benefits arising from heterosis or from the production of phenotypes intermediate between the parental phenotypes that provide better resistance to stressful conditions and/or the ability to survive in particular habitats (Burke \& Arnold 2001). However, hybridization is almost invariably associated with the rupture of

Correspondence: Tanja Schwander, Fax: +41 2169241 65; E-mail: tanja.schwander@unil.ch co-adapted gene complexes (Barton \& Hewitt 1985) or genetic incompatibilities (Kulathinal \& Singh 1998; Greig et al. 2002; Orr 2005) that generally translate into reduced fecundity or sterility of hybrids (Burke \& Arnold 2001).

The existence of reproductive division of labour, as occurs in social insect species, potentially provides a situation allowing the expression of the positive effects of hybridization without the negative effects at reproduction. This would be the case if there was an association between hybridization and reproductive roles within colonies, with hybrids becoming non-reproductive helpers (i.e. workers) and non-hybrids preferentially developing into reproductive individuals (i.e. queens) (Umphrey \& Danzmann 1998; Hotz et al. 1999; Helms Cahan \& Vinson 2003; Umphrey 
2006). Interestingly, two such cases have been documented in ants. The first is in a hybrid zone between two fire ants: Solenopsis geminata and Solenopsis xyloni (Hung \& Vinson 1977; Helms Cahan \& Vinson 2003). Colonies contain several S. xyloni queens, each mated to either an S. geminata male or $S$. xyloni male; the first category of queens produce exclusively workers, whereas the second category of queens are specialized in queen production.

The second system has been documented in several populations of harvester ants of the genus Pogonomyrmex (Helms Cahan et al. 2002; Julian et al. 2002; Volny \& Gordon 2002a; Helms Cahan \& Keller 2003). In each case, a given population comprises two genetically distinct lineages (Helms Cahan \& Keller 2003; Schwander et al. 2007) and queens (which can be of either lineage) generally mate with males of their own and of the alternate lineage (Helms Cahan et al. 2004; Schwander et al. 2006). Colonies are headed by single queens whose pure-lineage female offspring develop into new queens while interlineage female offspring mostly develop into workers (Helms Cahan et al. 2002; Julian et al. 2002; Volny \& Gordon 2002a; Helms Cahan \& Keller 2003).

This genotype-based segregation of reproductive roles, referred to as genetic caste determination, incurs costs because queens apparently mate randomly with males of both lineages and indiscriminately use their sperm (Helms Cahan et al. 2004; Anderson et al. 2006b; Schwander et al. 2006). Thus, queens cannot adapt the proportion of queenand worker-destined eggs according to colony need. For example, during the time of colony founding (where only workers are produced) the number of worker offspring produced in the first cohort is negatively correlated with the proportion of pure-lineage eggs laid by the queen (Schwander et al. 2006). This is because almost all eggs fertilized by males of the same lineage as the queen die before hatching (Helms Cahan et al. 2004; Schwander et al. 2006).

Despite its apparent costs, genetic caste determination is widespread and has been documented in many locations throughout Arizona, New Mexico and Texas (Anderson et al. 2006a; Schwander et al. 2007). Genetic analyses revealed the existence of eight distinct lineages which invariably co-occur in the same four lineage pairs (the lineage $F_{1}$ co-occurs with the lineage $\mathrm{F}_{2}, \mathrm{G}_{1}$ with $\mathrm{G}_{2}, \mathrm{H}_{1}$ with $\mathrm{H}_{2}$, and $\mathrm{J}_{1}$ with $\mathrm{J}_{2}$ (Schwander et al. 2007). All lineages have evolved following complex hybridization events between Pogonomyrmex rugosus and Pogonomyrmex barbatus (Helms Cahan \& Keller 2003; Schwander et al. 2007; but see Anderson et al. 2006a). Three $\left(F_{1}-F_{2}, G_{1}-G_{2}\right.$ and $\left.H_{1}-H_{2}\right)$ of the four lineage pairs are morphologically similar to $P$. rugosus and apparently evolved from a single ancestral lineage pair. Individuals of the fourth lineage pair $\left(\mathrm{J}_{1}-\mathrm{J}_{2}\right)$ are morphologically similar to $P$. barbatus and the relationship between this lineage pair and the others is unclear (Schwander et al. 2007).
Several studies have reported the occurrence of interlineage daughter queens in a small proportion of field colonies (Helms Cahan et al. 2002; Julian et al. 2002; Helms Cahan \& Keller 2003; Helms Cahan et al. 2004). These are potentially important because, if successful, interlineage queens could provide a route for gene flow between interbreeding lineages and ultimately lead to the loss of two distinct gene pools in these populations. However, genetic studies have revealed a complete lack of gene flow between lineages as well as between lineages and the parental species (Helms Cahan \& Keller 2003; Anderson et al. 2006a; Helms Cahan et al. 2006; Schwander et al. 2007). Thus, it appears that these interlineage queens fail to mediate genetic introgression between lineages.

This study has two general aims. The first is to determine under which conditions interlineage queens are produced. It has been suggested that interlineage queens are primarily produced by colonies headed by queens who mate only with males of the alternate lineage (Helms Cahan et al. 2002; Helms Cahan \& Keller 2003). To test this idea, we first examine theoretically how variation in the proportions of the two lineages within a population should affect the frequency of queens exclusively mated with males of the alternate lineage. We then test whether there is a positive association across 26 populations between the expected proportion of such queens and the frequency of field colonies producing interlineage daughter queens.

The second aim of this study is to identify the stage at which selection against interlineage queens occurs. To this end, we compared the frequency of interlineage queens across three key stages of the colony life cycle in a wellstudied population at Hidalgo, New Mexico. With the help of diagnostic microsatellites, we first assessed the frequency of established colonies producing interlineage queens. Second, we determined the frequency of interlineage queens after the mating flight when queens initiate new colonies. Third, we estimated the proportion of established colonies headed by interlineage queens. This allowed us to show that interlineage queens disappear from the population between colony initiation and maturity. In a further laboratory experiment, we tested possible reasons for this low success by comparing weight, fecundity, egg survival, energy investment and overall productivity of intra- and interlineage queens during the period of colony founding.

\section{Methods}

Previous studies (Helms Cahan et al. 2004; Schwander et al. 2006) strongly suggested that queens mate randomly with males of their own and of the alternate lineage in the mating flight. Under random mating, the expected proportion of queens exclusively mated to males of the alternate lineage, which we refer to as cross-mated queens, depends on the 
frequency of each lineage in the mating flight and on the number of mates per queen. The number of mates per queen is important because it influences the probability for queens mating with at least one male of their own lineage. We thus determined the expected frequency of exclusively cross-mated queens as $\left(1-p_{1}\right) p_{1}^{m}+p_{1}\left(1-p_{1}\right)^{m}$, where $p_{1}$ is the proportion of lineage 1 in the population and $m$ is the number of (absolute) matings per queen. An average of six matings has been estimated for Pogonomyrmex rugosus (Gadau et al. 2003) and similar mating frequencies occur in the $\mathrm{H}_{1}$ and $\mathrm{H}_{2}$ lineages (average number of mates per queen \pm SE: $6.11 \pm 0.20$, Helms Cahan \& Julian, in preparation). We calculated the expected proportion of crossmated queens as a function of relative lineage frequencies assuming four, six or eight matings per queen.

We then estimated the relative frequencies of the two lineages and the proportion of colonies producing interlineage queens at 26 sites in Texas, New Mexico and Arizona to compare the observed proportion of colonies producing interlineage queens to expected proportions of crossmated queens. The 26 sites included nine with the $F_{1}-F_{2}$ lineage pair, two with the $G_{1}-G_{2}$ lineage pair, nine with the $\mathrm{H}_{1}-\mathrm{H}_{2}$ lineage pair and six with the $\mathrm{J}_{1}-\mathrm{J}_{2}$ lineage pair. At a large scale, the relative frequencies of the two lineages in queens heading established colonies roughly equal the frequencies of queens and males in the mating flight (Helms Cahan et al. 2004; Schwander et al. 2006). We used previously published frequency data of colonies from Schwander et al. (2007), with additional genotyping of colonies producing either interlineage queens or exclusively male reproductive offspring, neither of which had been included in that study. To determine the maternal lineage of the former colonies, we sequenced the 433-bp portion of the Cox1 gene of one interlineage queen as described in Helms Cahan \& Keller (2003). The assignment of haplotypes to the lineages of a given pair is unambiguous as each of the eight lineages is characterized by a specific set of haplotypes (Schwander et al. 2007). To identify the maternal lineage of colonies with only males, we determined the colour of the males produced in the colonies for the 20 sites with the $\mathrm{F}_{1}-\mathrm{F}_{2}, \mathrm{G}_{1}-\mathrm{G}_{2}$ and $\mathrm{H}_{1}-\mathrm{H}_{2}$ lineages (males produced by $\mathrm{F}_{1}-\mathrm{F}_{1}, \mathrm{G}_{1}-\mathrm{G}_{1}$ and $\mathrm{H}_{1}-\mathrm{H}_{1}$ queens have a red thorax while males produced by colonies headed by $\mathrm{F}_{2}-\mathrm{F}_{2}, \mathrm{G}_{2}-\mathrm{G}_{2}$ and $\mathrm{H}_{2}-\mathrm{H}_{2}$ queens have a black thorax (Helms Cahan et al. 2002; Helms Cahan \& Keller 2003; Schwander et al. 2007). Because males of the $\mathrm{J}_{1}$ and $\mathrm{J}_{2}$ lineages cannot be distinguished morphologically, we determined their lineage by analysing diagnostic restriction fragments of the Cox1 gene from one worker as described in Schwander et al. (2006). Overall, we were able to determine the maternal lineage of 1044 colonies, 141 of the $\mathrm{J}_{1}-\mathrm{J}_{2}$ lineages, 488 of the $\mathrm{F}_{1}-\mathrm{F}_{2}$ lineages, 60 of the $\mathrm{G}_{1}-\mathrm{G}_{2}$ lineages and 355 of the $\mathrm{H}_{1}-\mathrm{H}_{2}$ lineages.

To investigate at which stage of the colony life cycle interlineage queens are lost from the population, we focused on a well-studied population at Hidalgo, New Mexico containing the genetic lineages $\mathrm{H}_{1}$ and $\mathrm{H}_{2}$ (Helms Cahan et al. 2002; Julian et al. 2002; Helms Cahan \& Keller 2003). We compared the frequencies of $\mathrm{H}_{1}-\mathrm{H}_{2}$ interlineage queens across three key stages of the colony life cycle. First, we quantified the proportion of mature colonies producing interlineage daughter queens by genotyping a single winged queen ( $n=155$ colonies) at one out of three microsatellite loci known to have fixed differences for the two lineages in the Hidalgo population ( $\mathrm{Pb}-5, \mathrm{~Pb}-7, \mathrm{~Pb}-8$ from Volny \& Gordon 2002b; Helms Cahan \& Keller 2003). Whenever we found an interlineage daughter queen, we genotyped five to six additional queens to ascertain whether these colonies produced exclusively interlineage queens. Second, we genotyped 737 newly mated queens just after a mating flight in the same population. Finally, we estimated the proportion of interlineage queens heading established colonies by collecting two workers from all colonies where workers were foraging $(n=267)$ and genotyping them at the same three microsatellite markers as well as at PR-1 from Gadau et al. (2003) which was also thought to have fixed differences between lineages (Schwander et al. 2006). To confirm that interlineage queens produce recombinant gametes, we genotyped 10 workers from each of six laboratory colonies headed by interlineage queens, which all showed backcross genotypes as expected (T. Schwander, unpublished data). Thus, the presence of backcross workers would indicate a colony headed by an interlineage queen. The probability of wrongly classifying an interlineage queen as a pure-lineage queen (i.e. her two daughter workers had an interlineage genotype at all four microsatellite markers) was about $0.5^{8} \sim 0.004$. While conducting these analyses we found that the locus PR-1 actually had one $\mathrm{H}_{1}$-allele (allele 394 ) which occurred at about $0.5 \%$ in the lineage $\mathrm{H}_{2}$. Therefore, when one or the two workers were homozygous for allele 394 at PR-1, we genotyped eight additional workers at $\mathrm{Pb}-5, \mathrm{~Pb}-7 \mathrm{and} \mathrm{Pb}-8$, to determine whether the queen had an intra or interlineage genotype.

To compare the performance of interlineage queens and pure-lineage queens during colony founding, we collected and weighed 1087 queens to the nearest $\mu \mathrm{g}$ immediately after mating flights at Hidalgo and raised them under standard laboratory conditions (Helms Cahan et al. 2004; Schwander et al. 2006). The live weight before colony founding was measured because it is correlated to the probability of survival in queens with independent colony founding (Wiernasz \& Cole 2003; Fjerdingstad \& Keller 2004) as well as to productivity (Wagner \& Gordon 1999; Liu et al. 2001; DeHeer 2002). To compare the fecundity of intra- and interlineage queens, we counted the number of eggs (and small larvae if present) produced after 2 weeks, when the first larvae start to hatch (Helms Cahan et al. 2004). After 6 weeks, last instar larvae, pupae and workers were counted and the 947 surviving queens were reweighed. 
We also determined the lineage of each queen and identified interlineage queens by genotyping a piece of the midhind leg at one of the diagnositic microsatellite loci. We then transferred all colonies headed by interlineage queens and a similar number of colonies headed by $\mathrm{H}_{1}-\mathrm{H}_{1}$ and $\mathrm{H}_{2}$ $\mathrm{H}_{2}$ pure-lineage queens into $13 \times 13 \times 8.5 \mathrm{~cm}$ boxes where they were fed ad libitum with seeds and mealworms. We counted the number of workers of each colony at weeks 12 and 24 after the mating flight. Finally, we compared the viability of eggs laid by pure-lineage and interlineage queens by microsatellite genotyping. Because of the rapid degradation of DNA, dead eggs cannot be successfully genotyped (Schwander et al. 2006). The proportion of amplifiable eggs was therefore used as a measure of the proportion of viable eggs. We genotyped $10024-h-$ to 48 -hold eggs laid by interlineage queens (20 eggs for each of 5 queens) and 245 24-h- to 48-h-old eggs laid by pure-lineage $\mathrm{H}_{1}-\mathrm{H}_{1}$ and $\mathrm{H}_{2}-\mathrm{H}_{2}$ queens (8-10 eggs per queen for $25 \mathrm{H}_{1}-\mathrm{H}_{1}$ queens and $27 \mathrm{H}_{2}-\mathrm{H}_{2}$ queens) following the methods described in Schwander et al. (2006).
For all adults, DNA was extracted in $150 \mu \mathrm{L}$ of $5 \%$ Chelex (Sigma-Aldrich) at $95^{\circ} \mathrm{C}$ for $20 \mathrm{~min}$. Polymerase chain reactions (PCR) were performed as described in Helms Cahan \& Keller (2003) except for PR-1 where the hybridization temperature in the PCR cycles was set to $54^{\circ} \mathrm{C}$. Amplified fluorescent fragments were visualized on $5 \%$ polyacrylamide/ $6 \mathrm{~m}$ urea sequencing gels using an automated ABI PRISM 377 sequencer. Gels were analysed with GENESCAN version 3.1.2 software (Applied Biosystems).

\section{Results}

Colonies producing interlineage queens were found at low to moderate proportions $(0.05-0.18)$ in the three lineage pairs with individuals morphologically similar to Pogonomyrmex rugosus (i.e. $\mathrm{F}_{1}-\mathrm{F}_{2}, \mathrm{G}_{1}-\mathrm{G}_{2}$ and $\mathrm{H}_{1}-\mathrm{H}_{2}$ ). These colonies were found in six out of the nine sites comprising the lineage pair $\mathrm{F}_{1}-\mathrm{F}_{2}$, in both of the two sites comprising the lineage pair $\mathrm{G}_{1}-\mathrm{G}_{2}$ and in eight out of the nine $\mathrm{H}_{1}-\mathrm{H}_{2}$ sites (Table 1 ). Five to six additional queens from these same colonies were

Table 1 Sample sizes (proportions) for the number of colonies headed by queens of each lineage and for the number of colonies producing pure-lineage and interlineage daughter queens. Lin1, lineage $1\left(\mathrm{~J}_{1}, \mathrm{~F}_{1}, \mathrm{G}_{1}\right.$ or $\left.\mathrm{H}_{1}\right)$; Lin2, lineage $2\left(\mathrm{~J}_{2}, \mathrm{~F}_{2}, \mathrm{G}_{2}\right.$ or $\left.\mathrm{H}_{2}\right)$; mLin1, maternal lineage 1; mLin2, maternal lineage 2 . Values for the rare lineage in each population are labelled with*

\begin{tabular}{|c|c|c|c|c|c|c|c|c|c|c|c|c|}
\hline \multirow[b]{2}{*}{ Site } & \multirow[b]{2}{*}{ State } & \multirow[b]{2}{*}{ Coordinates } & \multirow[b]{2}{*}{ Lineages } & \multicolumn{3}{|c|}{ Number of colonies } & \multicolumn{4}{|c|}{$\begin{array}{l}\text { Number of daughter } \\
\text { queen genotypes }\end{array}$} & \multirow{2}{*}{$\begin{array}{l}\text { Interlineage } \\
\text { mL1 }\end{array}$} & \multirow{2}{*}{$\begin{array}{l}\text { Interlineage } \\
\mathrm{mL} 2\end{array}$} \\
\hline & & & & Total & $\operatorname{Lin} 1$ & $\operatorname{Lin} 2$ & Total & Lin1 & $\operatorname{Lin} 2$ & L1-L2 & & \\
\hline 113 & NM & $\mathrm{N} 32^{\circ} 13.522, \mathrm{~W} 108^{\circ} 32.230$ & $\mathrm{~J}$ & 26 & $10(0.38)^{*}$ & $16(0.62)$ & 18 & 7 & 11 & $0(0.00)$ & $0(0.00)^{*}$ & $0(0.00)$ \\
\hline $\mathrm{H}$ & NM & $\mathrm{N} 32^{\circ} 24.971, \mathrm{~W} 109^{\circ} 39.930$ & $\mathrm{~J}$ & 16 & $4(0.25)^{*}$ & $12(0.75)$ & 16 & 4 & 12 & $0(0.00)$ & $0(0.00)^{*}$ & $0(0.00)$ \\
\hline Mon & $\mathrm{AZ}$ & $\mathrm{N} 32^{\circ} 00.067, \mathrm{~W} 109^{\circ} 23.106$ & $\mathrm{~J}$ & 19 & $2(0.11)^{*}$ & $17(0.89)$ & 19 & 2 & 17 & $0(0.00)$ & $0(0.00)^{*}$ & $0(0.00)$ \\
\hline SH & NM & $\mathrm{N} 31^{\circ} 44.618, \mathrm{~W} 109^{\circ} 05.717$ & $\mathrm{~J}$ & 21 & $9(0.43)^{*}$ & $12(0.57)$ & 14 & 6 & 8 & $0(0.00)$ & $0(0.00)^{*}$ & $0(0.00)$ \\
\hline SL & NM & $\mathrm{N} 31^{\circ} 00.001, \mathrm{~W} 108^{\circ} 58.000$ & $\mathrm{~J}$ & 15 & $6(0.40)^{*}$ & $9(0.60)$ & 15 & 6 & 9 & $0(0.00)$ & $0(0.00)^{*}$ & $0(0.00)$ \\
\hline Junction & $\mathrm{NM}$ & $\mathrm{N} 31^{\circ} 50.725, \mathrm{~W} 109^{\circ} 02.956$ & $\mathrm{~J}$ & 44 & $15(0.34)^{*}$ & $29(0.66)$ & 35 & 12 & 23 & $0(0.00)$ & $0(0.00)^{*}$ & $0(0.00)$ \\
\hline $\mathrm{AN}$ & NM & $\mathrm{N} 33^{\circ} 26.000, \mathrm{~W} 104^{\circ} 39.000$ & $\mathrm{~F}$ & 51 & $12(0.24)^{*}$ & $39(0.76)$ & 33 & 9 & 24 & $4(0.11)$ & $2(0.50)^{*}$ & $2(0.50)$ \\
\hline $\mathrm{BF}$ & $\mathrm{TX}$ & $\mathrm{N} 30^{\circ} 41.606, \mathrm{~W} 101^{\circ} 27.610$ & $\mathrm{~F}$ & 18 & $12(0.67)$ & $6(0.33)^{*}$ & 13 & 9 & 4 & $2(0.13)$ & $1(0.50)$ & $1(0.50)^{*}$ \\
\hline ENT & $\mathrm{TX}$ & $\mathrm{N} 30^{\circ} 19.205, \mathrm{~W} 104^{\circ} 05.183$ & $\mathrm{~F}$ & 26 & $13(0.5)$ & $13(0.5)$ & 26 & 13 & 13 & $0(0.00)$ & $0(0.00)$ & $0(0.00)$ \\
\hline Hidalgo & NM & $\mathrm{N} 32^{\circ} 23.391, \mathrm{~W} 104^{\circ} 13.214$ & $\mathrm{~F}$ & 202 & $135(0.67)$ & $67(0.33)^{*}$ & 147 & 95 & 52 & $8(0.05)$ & $4(0.50)$ & $4(0.50)^{*}$ \\
\hline UFO & NM & $\mathrm{N} 33^{\circ} 23.619, \mathrm{~W} 104^{\circ} 41.240$ & $\mathrm{~F}$ & 18 & $8(0.44)^{*}$ & $10(0.56)$ & 18 & 8 & 10 & $0(0.00)$ & $0(0.00)^{*}$ & $0(0.00)$ \\
\hline GS & TX & $\mathrm{N} 31^{\circ} 45.820, \mathrm{~W} 104^{\circ} 55.615$ & $\mathrm{~F}$ & 39 & $25(0.64)$ & $14(0.36)^{*}$ & 29 & 19 & 10 & $2(0.06)$ & $1(0.50)$ & $1(0.50)^{*}$ \\
\hline SS & $\mathrm{TX}$ & $\mathrm{N} 31^{\circ} 49.393, \mathrm{~W} 103^{\circ} 54.551$ & $\mathrm{~F}$ & 21 & $2(0.10)^{*}$ & $19(0.90)$ & 14 & 0 & 14 & $3(0.18)$ & $1(0.33)^{*}$ & $2(0.67)$ \\
\hline PC & $\mathrm{TX}$ & $\mathrm{N} 30^{\circ} 40.221, \mathrm{~W} 101^{\circ} 40.571$ & $\mathrm{~F}$ & 82 & $12(0.15)^{*}$ & $70(0.85)$ & 70 & 7 & 63 & $12(0.14)$ & $5(0.42)^{*}$ & $7(0.58)$ \\
\hline $\mathrm{HE}$ & $\mathrm{TX}$ & $\mathrm{N} 30^{\circ} 21.678, \mathrm{~W} 103^{\circ} 38.683$ & $\mathrm{~F}$ & 31 & $12(0.39)^{*}$ & $19(0.61)$ & 29 & 10 & 19 & $2(0.06)$ & $2(1.00)^{*}$ & $0(0.00)$ \\
\hline MF & NM & N3255.049, W10557.809 & G & 23 & $14(0.61)$ & $9(0.39)^{*}$ & 19 & 10 & 9 & $2(0.09)$ & $2(1.00)$ & $0(0.00)^{*}$ \\
\hline Carls & $\mathrm{TX}$ & $\mathrm{N} 32^{\circ} 48.990, \mathrm{~W} 103^{\circ} 14.250$ & G & 37 & $32(0.86)$ & $5(0.14)^{*}$ & 29 & 26 & 3 & $4(0.12)$ & $3(0.75)$ & $1(0.25)^{*}$ \\
\hline Ala & NM & $\mathrm{N} 31^{\circ} 57.775, \mathrm{~W} 108^{\circ} 48.923$ & $\mathrm{H}$ & 36 & $26(0.72)$ & $10(0.28)^{*}$ & 23 & 18 & 5 & $2(0.08)$ & $1(0.50)$ & $1(0.50)^{*}$ \\
\hline Elp & NM & $\mathrm{N} 31^{\circ} 55.696, \mathrm{~W} 108^{\circ} 22.284$ & $\mathrm{H}$ & 31 & $14(0.45)^{*}$ & $17(0.55)$ & 24 & 11 & 13 & $2(0.08)$ & $1(0.50)$ & $1(0.50)$ \\
\hline Hob & NM & $\mathrm{N} 31^{\circ} 59.757, \mathrm{~W} 109^{\circ} 02.362$ & $\mathrm{H}$ & 29 & $15(0.52)$ & $14(0.48)^{*}$ & 25 & 12 & 13 & $2(0.07)$ & $1(0.50)$ & $1(0.50)^{*}$ \\
\hline LC & NM & $\mathrm{N} 31^{\circ} 55.121, \mathrm{~W} 109^{\circ} 02.969$ & $\mathrm{H}$ & 41 & $31(0.76)$ & $10(0.24)^{*}$ & 28 & 23 & 5 & $3(0.10)$ & $1(0.33)$ & $2(0.67)^{*}$ \\
\hline Ros & $\mathrm{AZ}$ & $\mathrm{N} 32^{\circ} 16.214, \mathrm{~W} 109^{\circ} 14.300$ & $\mathrm{H}$ & 56 & $33(0.59)$ & $23(0.41)^{*}$ & 36 & 18 & 18 & $5(0.12)$ & $1(0.20)$ & $4(0.80)^{*}$ \\
\hline SF & $\mathrm{AZ}$ & $\mathrm{N} 32^{\circ} 12.887, \mathrm{~W} 109^{\circ} 10.573$ & $\mathrm{H}$ & 29 & $15(0.52)$ & $14(0.48)^{*}$ & 22 & 12 & 10 & $0(0.00)$ & $0(0.00)$ & $0(0.00)^{*}$ \\
\hline Or & $\mathrm{AZ}$ & $\mathrm{N} 32^{\circ} 17.555, \mathrm{~W} 109^{\circ} 20.235$ & $\mathrm{H}$ & 51 & $33(0.65)$ & $18(0.35)^{*}$ & 40 & 25 & 15 & $4(0.09)$ & $2(0.50)$ & $2(0.50)^{*}$ \\
\hline $\mathrm{Fl}$ & TX & $\mathrm{N} 31^{\circ} 50.061, \mathrm{~W} 106^{\circ} 32.704$ & $\mathrm{H}$ & 58 & $30(0.52)$ & $28(0.48)^{*}$ & 23 & 12 & 11 & $0(0.00)$ & $0(0.00)$ & $0(0.00)^{*}$ \\
\hline Alp & NM & $\mathrm{N} 32^{\circ} 24.384, \mathrm{~W} 106^{\circ} 39.318$ & $\mathrm{H}$ & 24 & $9(0.38)^{*}$ & $15(0.63)$ & 19 & 9 & 10 & $1(0.05)$ & $1(1.00)^{*}$ & $0(0.00)$ \\
\hline
\end{tabular}


all also of interlineage genotype, suggesting that no purelineage individuals were present in these colonies. In contrast, not a single interlineage queen was found in any of the six sites with the Pogonomyrmex barbatus-like lineage pair $\mathrm{J}_{1}-\mathrm{J}_{2}$ (117 colonies, Table 1), resulting in a significantly lower proportion of interlineage queens in the $\mathrm{J}_{1}-\mathrm{J}_{2}$ lineage pairs than in the $F_{1}-F_{2}, G_{1}-G_{2}$ and $H_{1}-H_{2}$ lineage pairs (Fisher's exact test $P=0.0004$ ). The lack of interlineage queens in $\mathrm{J}_{1^{-}}$ $\mathrm{J}_{2}$ populations was not due to more balanced frequencies of the two lineages at these sites relative to sites with other lineages (absolute difference between the proportions of the co-occurring lineages in $\mathrm{J}_{1}-\mathrm{J}_{2}$ populations: 0.36 , for populations with other lineage pairs: 0.30 ; $t$-test on arcsin and square root transformed data: $t_{10.1}=0.85, P=0.42$, Table 1). Because these two sets of lineages differed significantly, they were considered separately in all subsequent analyses.

Our model shows that, with the exception of extremely skewed proportions of the two lineages, the expected frequency of queens exclusively mated to males of the alternate lineage (cross-mated queens) increases when the proportions of the two lineages in the mating flight are more unbalanced (Fig. 1). The maximum frequency of cross-mated queens is reached when the proportion of the rare lineage is between 0.1 and 0.2 , the exact value depending on the number of matings by queens (Fig. 1). (When the proportion of the two lineages becomes more extremely skewed, the frequency of cross-mated queens decreases because queens of the rare lineage, which are mostly crossmated, virtually disappear from the population.) Given that the observed frequencies of the rare lineage in the studied

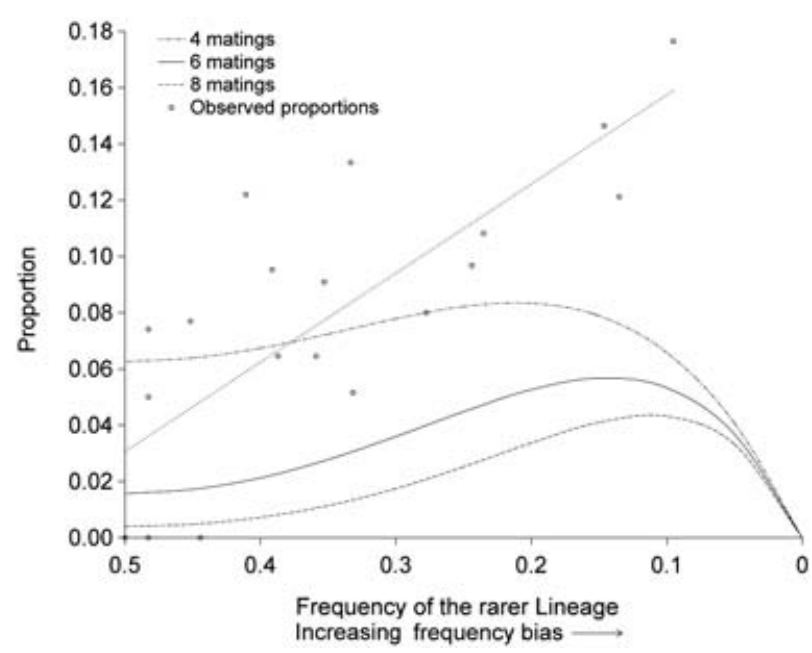

Fig. 1 Expected proportions (dotted and continuous curves) of queens exclusively mated to males of the alternate lineage (crossmated queens) and observed proportions (dots) of colonies producing interlineage queens in 20 populations with the lineages $\mathrm{F}, \mathrm{G}$ or $\mathrm{H}$ in relation to the frequency of the rarer lineage in the population. populations were between $10 \%$ and $50 \%$, the expected proportion of cross-mated queens continuously increases with the degree of skew in the proportion of co-occurring lineages across the 20 populations studied. To test the hypothesis that interlineage queens are produced by colonies headed by cross-mated queens, we therefore tested whether there was a positive association across populations between the proportion of colonies producing interlineage queens and the skew of the observed frequencies of the two lineages. This analysis indeed revealed a positive significant correlation (Pearson's product-moment correlation rho $=0.78, t_{18}=5.76, P<0.0001$, Fig. 1 ).

Another prediction stemming from the hypothesis that interlineage queens are produced by colonies headed by cross-mated queens is that colonies producing interlineage queens should more frequently be headed by queens of the rare lineage than colonies producing pure-lineage queens (this is because queens of the rare lineage are more likely to mate exclusively with males of the alternate lineage than queens of the frequent lineage). This prediction was also supported by our data showing that the frequency of the two lineages was more balanced for queens heading colonies producing interlineage queens than for queens heading colonies producing pure-lineage queens (sign test, $P=0.004)$.

There was a significant overall excess of colonies producing interlineage queens in the $\mathrm{F}_{1}-\mathrm{F}_{2}, \mathrm{G}_{1}-\mathrm{G}_{2}$ and $\mathrm{H}_{1}-\mathrm{H}_{2}$ populations compared to the predicted values for six matings per queen (sign test: $P=0.012$, Fig. 1 ). The observed frequency of colonies producing interlineage queens was larger than predicted in 16 out of the 20 studied populations. The magnitude of this excess increased significantly with increasingly skewed proportions of the two lineages (slope: $2.48 \pm 0.56$ and significantly bigger than $1: t_{18}=2.64$; $P=0.016$, Fig. 1). In contrast to the $\mathrm{F}_{1}-\mathrm{F}_{2}, \mathrm{G}_{1}-\mathrm{G}_{2}$ and $\mathrm{H}_{1}-\mathrm{H}_{2}$ populations, we found a significant deficit of colonies producing interlineage queens in populations with the $\mathrm{J}_{1}-\mathrm{J}_{2}$ lineages. In all six populations, the observed proportion was lower than the expected value (sign test: $P=0.031$ ).

The comparison of the observed frequencies of $\mathrm{H}_{1}-\mathrm{H}_{2}$ interlineage queens at three stages of the colony life cycle in the population Hidalgo revealed that interlineage queens are produced and join the mating swarm but fail to establish colonies. Slightly over $5 \%$ of queen-producing colonies $(0.052, n=155)$ produced exclusively interlineage daughter queens. The proportion of interlineage queens (0.046) was similar among mated queens collected just after the mating swarm $\left(n=737 ; X_{1}^{2}=0.05, P=0.94\right)$. In contrast, we found that the proportion of interlineage queens heading established colonies (0.00) was significantly lower $\left(n=267 ; X_{1}^{2}=10.8, P=0.001\right)$. In 263 of these 267 colonies, the workers (two per colony) had genotypes at the four markers studied that were consistent with their mother queens being of pure-lineage origin. In the remaining 


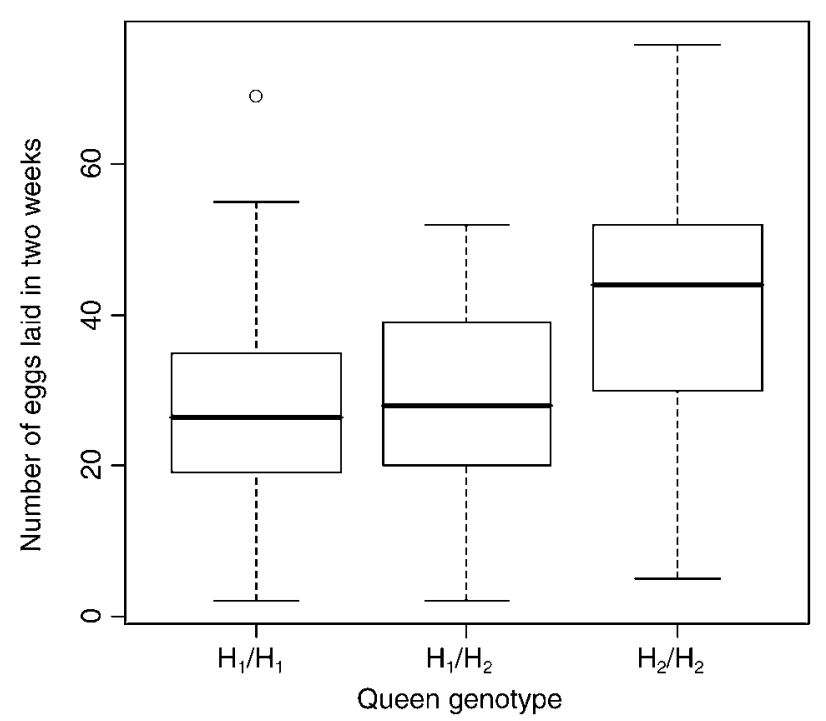

Fig. 2 Fecundity (the number of eggs laid during the first two weeks of independent colony founding) of pure- and interlineage queens. The boxes delimit the upper and lower quartiles; the horizontal lines indicate the median. Whiskers include $95 \%$ of all observations.

four colonies, workers had $\mathrm{F}_{1}$ interlineage genotypes at the three diagnostic markers but two typical $\mathrm{H}_{1}$ alleles at the nearly diagnostic marker PR-1 which might suggest backcrossing. However, genotyping of eight additional workers from each of these four colonies revealed that three of them were headed by an $\mathrm{H}_{2}-\mathrm{H}_{2}$ pure-lineage queen harbouring one $\mathrm{H}_{1}$ typical allele at PR-1 (allele 394). The remaining colony was headed by an $\mathrm{H}_{1}-\mathrm{H}_{1}$ pure-lineage queen mated with an $\mathrm{H}_{2}$ male also having the 394 allele at PR-1.

The laboratory studies showed that $\mathrm{H}_{1}-\mathrm{H}_{2}$ interlineage queens performed less well during colony founding than $\mathrm{H}_{1}-\mathrm{H} 1$ and $\mathrm{H}_{2}-\mathrm{H}_{2}$ pure-lineage queens. We found significant differences in egg production among the three classes of queens during the first two weeks of colony founding $\left(F_{2,123}=11.11, P<0.0001\right)$. This was due to $\mathrm{H}_{2}-\mathrm{H}_{2}$ queens laying significantly more eggs than both $\mathrm{H}_{1}-\mathrm{H}_{1}$ and $\mathrm{H}_{1}-\mathrm{H}_{2}$ queens (both Tukey posthoc tests $P<0.0001$, Fig. 2). Importantly, however, interlineage queens produced eggs with a lower viability $(0.31 ; 95 \%$ CI $0.24-0.39)$ than either $\mathrm{H}_{1}-\mathrm{H}_{1}(0.61)$ or $\mathrm{H}_{2}-\mathrm{H}_{2}(0.51)$ pure-lineage queens (fisher's exact tests: $\mathrm{H}_{1}-\mathrm{H}_{1}$ queens: $P=0.007, \mathrm{H}_{2}-\mathrm{H}_{2}$ queens: $P=0.037$, Fig. 3). These differences translated into interlineage queens producing fewer pupae and workers than $\mathrm{H}_{1-}$ $\mathrm{H}_{1}$ and $\mathrm{H}_{2}-\mathrm{H}_{2}$ queens and these differences in productivity increased through weeks 12 and 24 (repeated measures ANOva: main effect of queen genotype: $F_{2,50}=9.0, P=0.0002$, the three Tukey post hoc tests $P<0.05$, main effect of week: $F_{2,50}=12.1, P<0.0001$, interaction: $F_{1,50}=11.9, P<0.0001$, Fig. 4). Overall, interlineage queens produced about $40 \%$ fewer offspring than pure-lineage queens after six and

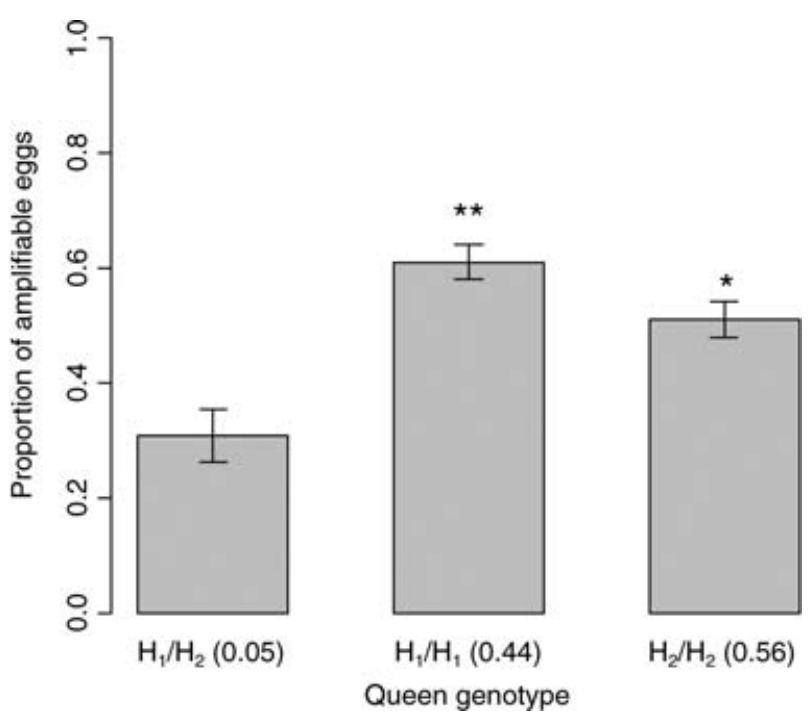

Fig. 3 Average proportions (and standard deviation) of viable eggs laid by pure- and interlineage queens estimated by the proportion of eggs of which DNA could be successfully extracted and amplified. Numbers in brackets indicate the frequency of queens of each genotype in the mating flight.

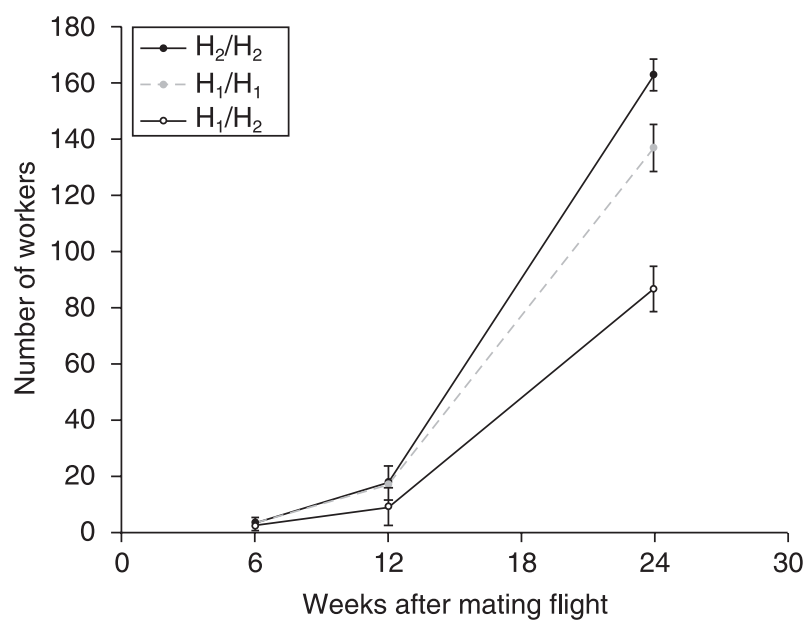

Fig. 4 Average number (and standard deviation) of offspring produced by pure- and interlineage queens after 6,12 and 24 weeks.

12 weeks of colony founding and about 50\% fewer offspring after 24 weeks (Fig. 4).

In addition to these productivity differences between inter- and pure-lineage queens, there were also productivity differences between the $\mathrm{H}_{1}-\mathrm{H}_{1}$ and $\mathrm{H}_{2}-\mathrm{H}_{2}$ pure-lineage queens that reflected the difference in fecundity between these two categories of queens. After 24 weeks, colonies headed by $\mathrm{H}_{2}-\mathrm{H}_{2}$ queens produced $16 \%$ more workers than colonies headed by $\mathrm{H}_{1}-\mathrm{H}_{1}$ queens (Tukey posthoc test $P<0.05)$. Productivity differences between the two types of colonies were not visible at weeks 6 and 12 (Fig. 4). 
(a)

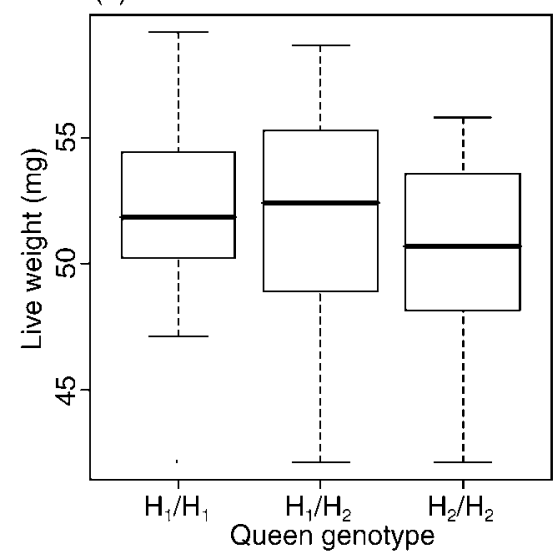

(b)

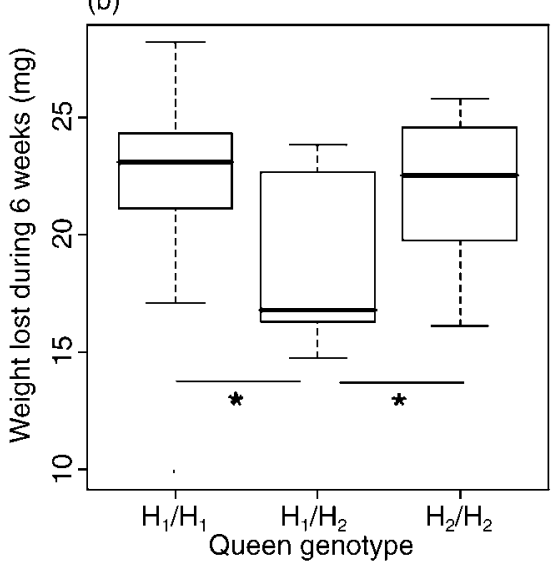

(c)

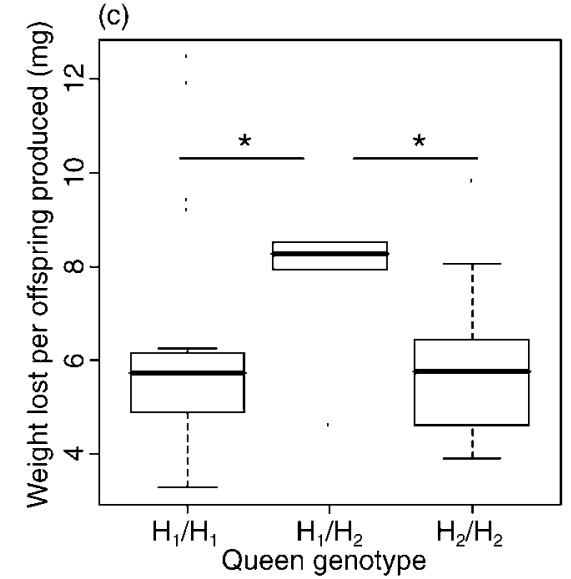

Fig. 5 (a) Live weight of pure- and interlineage queens after the mating flight (b) Total weight lost during 6 weeks of independent colony founding and (c) weight lost per individual offspring produced for pure- and interlineage queens. The boxes delimit the upper and lower quartiles; the horizontal lines indicate the median. Whiskers include $95 \%$ of all observations.

Although similar in weight after the mating flight $\left(F_{2,79}=\right.$ $1.46, P=0.24$, Fig. 5), interlineage queens lost significantly less weight than both types of pure-lineage queens during the six first weeks of colony founding $\left(\mathrm{K}-\mathrm{W} \mathrm{X} X_{2}^{2}=10.8\right.$, $P=0.018$, both post hocs $<0.03$, Fig. 5). However, interlineage queens lost significantly more weight per worker produced than both types of pure-lineage queens $(\mathrm{K}-\mathrm{W}$ $X_{2}^{2}=9.10, P=0.01$, both post hocs $<0.05$, Fig. 5).

\section{Discussion}

In some harvester ant lineages, queens are mostly produced from within-lineage matings while workers are produced from between-lineage matings because pure-lineage individuals have lost the ability to develop into workers. The occurrence of a small proportion of interlineage queens, which was reported in several previous studies (Helms Cahan et al. 2002; Julian et al. 2002; Helms Cahan \& Keller 2003; Anderson et al. 2006a; Schwander et al. 2007), could potentially lead to homogenization of interbreeding lineage genomes and hence to the loss of the genetic caste determination mechanism if such queens were consistently produced and reproductively fit. The results of the present study show that genetic isolation between lineages is maintained through different mechanisms in the $\mathrm{J}_{1}-\mathrm{J}_{2}$ than in the $\mathrm{F}_{1}-\mathrm{F}_{2}, \mathrm{G}_{1}-\mathrm{G}_{2}$ and $\mathrm{H}_{1}-\mathrm{H}_{2}$ lineage pairs. In the $\mathrm{J}_{1}-\mathrm{J}_{2}$ lineage pair, interlineage queens do not seem to be produced, so there is no opportunity for genetic introgression. In the $\mathrm{F}_{1}-\mathrm{F}_{2}, \mathrm{G}_{1}-\mathrm{G}_{2}$ and $\mathrm{H}_{1}-\mathrm{H}_{2}$ lineage pairs, a minority of colonies does produce exclusively interlineage queens, but these queens suffer fitness costs during colony foundation and growth and do not survive to reproductive age.

The proportion of colonies producing interlineage queens in the 20 sites with the lineage pairs $\mathrm{F}_{1}-\mathrm{F}_{2}, \mathrm{G}_{1}-\mathrm{G}_{2}$ or $\mathrm{H}_{1}-\mathrm{H}_{2}$ was typically small, but increased when the relative frequencies of the two lineages were less balanced (Fig. 1). As the proportion of queens that mate exclusively with males of the alternate lineage should also increase when the relative frequency of the two lineages become less balanced (Fig. 1), these patterns support the idea proposed by Helms Cahan et al. (2002) and Helms Cahan \& Keller (2003) that interlineage queens are produced only when no purelineage offspring are available for rearing. Thus, interlineage eggs from these lineages do not appear to be restricted in their caste fate in the absence of competition with purelineage brood.

The comparison of expected and observed proportions of colonies producing interlineage queens across sites with the $\mathrm{F}_{1}-\mathrm{F}_{2}, \mathrm{G}_{1}-\mathrm{G}_{2}$ and $\mathrm{H}_{1}-\mathrm{H}_{2}$ lineage pairs also revealed a significant overall excess of colonies producing interlineage queens, and this excess increased with increasingly unbalanced proportions of the two lineages in the population (Fig. 1). This is expected if, as suggested by laboratory studies, queens with more alternate-lineage mates are at a fitness advantage during colony founding and growth because more of their eggs are capable of developing into workers (Helms Cahan et al. 2004; Anderson et al. 2006b; Schwander et al. 2006). The magnitude of this fitness advantage should increase as the proportions of the two lineages become more skewed because the proportion of alternate-lineage matings decreases in the population as a whole (see Fig. 6 for illustration), thereby increasing the difference in numbers of workers produced by queens exclusively mated with males of the alternate lineage compared to the rest of the population (Helms Cahan et al. 2004; Schwander et al. 2006). Alternatively, a similar pattern might be obtained if colonies headed by queens mated to both lineages sometimes produced a small proportion of interlineage queens and if the proportion of such queens increased with increasingly unbalanced proportions of the two lineages in the population. 


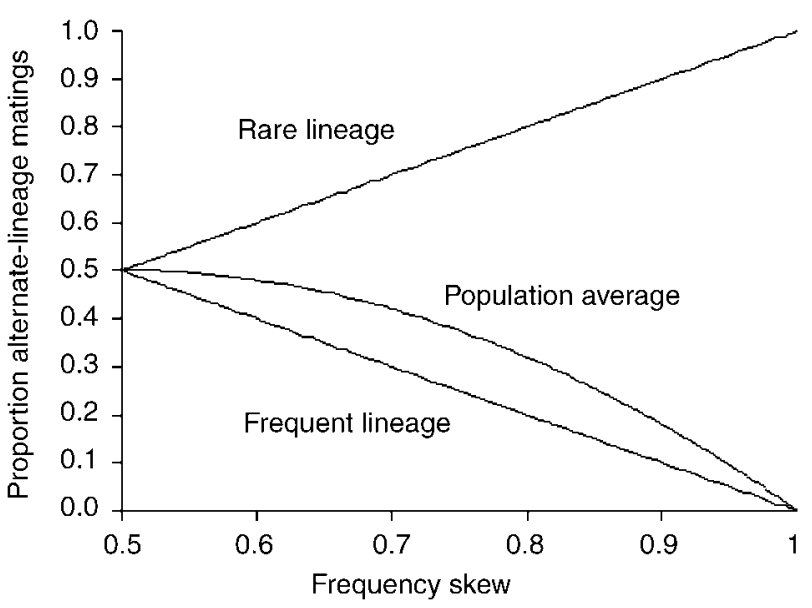

Fig. 6 The average proportion of alternate-lineage matings for the rare and the frequent lineage as well as the overall average in the population. The more unbalanced the relative frequencies of the two lineages are in the population, the lower the overall proportion of alternate-lineage matings.

In contrast to the $\mathrm{F}_{1}-\mathrm{F}_{2}, \mathrm{G}_{1}-\mathrm{G}_{2}$ and $\mathrm{H}_{1}-\mathrm{H}_{2}$ lineage pairs, we did not find a single interlineage queen in any of the $\operatorname{six} \mathrm{J}_{1}-\mathrm{J}_{2}$ populations despite the fact that the frequencies of the two lineages in these populations were similarly unbalanced. At least three, nonmutually exclusive mechanisms may account for the lack of $\mathrm{J}_{1}-\mathrm{J}_{2}$ interlineage queens. First, such queens might not be produced at all because caste determination is genetically more hardwired in the J lineages than in the other lineages, so that the developmental pathway to queens is not available for interlineage genotypes. Second, interlineage females may initiate queen development but not survive to maturity because of intrinsic mortality or culling by workers. Finally, mature interlineage queens may be produced at extremely low frequencies because few $\mathrm{J}_{1}-\mathrm{J}_{1}$ and $\mathrm{J}_{2}-\mathrm{J}_{2}$ queens mate exclusively with males of the alternate lineage, either because the proportions of the lineages in the mating flight are more balanced than in established colonies or through high levels of polyandry or assortative mating.

A difference in interlineage queen production between the $\mathrm{H}_{1}-\mathrm{H}_{2}$ and $\mathrm{J}_{1}-\mathrm{J}_{2}$ lineage pairs was previously noted by Anderson et al. (2006a), based on a review of published estimates of interlineage queen frequencies from various studies. They suggested that this trend indicated differences in the relative ages of genetic caste determination in the $\mathrm{H}_{1}-\mathrm{H}_{2}$ and $\mathrm{J}_{1}-\mathrm{J}_{2}$ populations, with production of interlineage queens being a transitory stage in the evolution of a 'complete' genetic caste determination mechanism. Although this is a possibility, it is equally likely that these represent two stable, alternative patterns of interlineage queen production. The $\mathrm{F}_{1}-\mathrm{F}_{2}, \mathrm{G}_{1}-\mathrm{G}_{2}$ and $\mathrm{H}_{1}-\mathrm{H}_{2}$ lineages all show similar levels of interlineage queen production and share a common evolutionary history (Schwander et al.
2007), suggesting that their common ancestor may have produced interlineage queens at the levels currently observed. In contrast, the relationship between this group of lineages and the $\mathrm{J}_{1}-\mathrm{J}_{2}$ lineage pair is controversial and may represent a separate origin of genetic caste determination (Anderson et al. 2006a; Schwander et al. 2007). Moreover, a consistent difference in interlineage queen production could explain observed differences in phylogenetic patterns between the two groups of lineages. Although each of the six lineages $\mathrm{F}_{1}-\mathrm{F}_{2}, \mathrm{G}_{1}-\mathrm{G}_{2}$ and $\mathrm{H}_{1}-\mathrm{H}_{2}$ has a characteristic set of mitochondrial haplotypes, the haplotypes do not cluster in six distinct clades but are somewhat intermixed. This might suggest that interlineage queens were produced historically with some small percentage surviving and mediating rare events of horizontal gene transfer. Importantly, there is no such evidence of historical mitochondrial introgression for the $\mathrm{J}_{1}-\mathrm{J}_{2}$ lineages, consistent with the hypothesis that interlineage queens have never been produced in appreciable numbers in this lineage pair.

Our survey of the Hidalgo population suggests that, when interlineage queens do occur, lineages with genetic caste determination remain highly differentiated because interlineage queens are less able to establish colonies than purelineage queens. Although some mature colonies produce exclusively interlineage queens, and these queens join the mating flight, mate and start to found new colonies, not a single established colony (out of 267) was headed by an interlineage queen. These results for the Hidalgo population are consistent with the trend observed over the entire range of the $F_{1}-F_{2}, G_{1}-G_{2}$, and $H_{1}-H_{2}$ lineage pairs. Microsatellite genotyping of daughter queens from 731 colonies over 26 sites revealed only four with genotypes suggestive of backcrossing, a global percentage of $0.5 \%$ (Schwander et al. 2007). This nearly complete reproductive isolation between interbreeding lineages has important implications for the interpretation of associations between alleles at individual marker loci and female caste. In the absence of recombination between lineages, any locus displaying allele frequency differences between lineages will show an association between genotype and female caste. As a consequence, the occurrence of such an association, even if strong, does not provide reliable information about the degree of physical linkage between marker loci and genes responsible for caste determination.

The low performance of interlineage queens at colony founding appears to be due to termination of a large proportion of their eggs before hatching (Fig. 3). Indeed, only $31 \%$ of eggs laid by interlineage queens were viable. Eggs that do not develop and that are not eaten by larvae are probably eaten by the queen herself, allowing her to recover some of the energy invested into aborting eggs. With fewer eggs hatching, these queens also have fewer larvae to raise than pure-lineage queens, which may explain why interlineage queens were heavier than pure-lineage queens 
after the 6 weeks of colony founding while there was no difference in weight just after the mating flight (Fig. 5). Low egg survival was also associated with higher peroffspring energy investment (Fig. 5) and a smaller number of workers produced (Fig. 4) for interlineage queens than for pure-lineage queens.

The low survival of eggs with backcrossed genotypes laid by interlineage queens may be due to the accumulation of neutral divergence between lineages or to problems during meiosis if chromosomes of the different lineages do not pair accurately. Such a pattern would be in accordance with the hypothesis suggested by Helms Cahan et al. (2002) and Julian et al. (2002) that genetic caste determination may have evolved to reduce fertility costs related to hybridization. If interlineage hybrids are intrinsically viable but reproductively unfit, colonies which turn hybrids into workers rather than queens should achieve higher reproductive success than colonies that expend resources on low-fitness queens. Alternatively, low fitness of interlineage queens may be a consequence rather than a cause of genetic caste determination. Once virtually all hybrid individuals develop into workers, the queen phenotype of interlineage genomes would become so rare that selection on queen functional traits might be ineffective relative to the potentially opposing effects of selection on the worker phenotype.

Low viability of backcross eggs may also be due directly to the genetic caste determination mechanism. It has been shown previously that queen-destined pure-lineage eggs abort very early in colonies of small size where only workers are reared (Helms Cahan et al. 2004; Schwander et al. 2006). Non-viable backcross eggs in small colonies might similarly be eggs with an inappropriate genotype for the worker developmental pathway. Three different types of genetic models have been proposed to explain how genotype determines caste fate in this system (Volny \& Gordon 2002a; Helms Cahan \& Keller 2003; Anderson et al. 2006a; Linksvayer et al. 2006). The simplest model, proposed by Volny \& Gordon (2002a), is based on a single caste determining locus with two alleles (a1 and a2) whereby heterozygotes (a1/a2) develop into workers and homozygotes (a1a1 or a2a2) into queens. Anderson et al. (2006a) expanded on this model by suggesting that a1/a2 genotypes are bipotential, but less predisposed than homozygotes to develop into queens. Under these single-locus models, interlineage queens (a1/a2) would produce an equal proportion of a1 and a 2 gametes, so that whatever type of male they mated with, $50 \%$ of eggs should be a1/a2 heterozygotes and thus be able to develop into workers. The second model proposed by Helms Cahan \& Keller (2003) is based on two loci (A and B) with two sets (A1 and A2, B1 and B2) of alleles each. Alleles at the two loci must interact to initiate worker development, but only alleles of the same set can interact successfully to trigger worker development (A1 alleles with B1 alleles, A2 alleles with B2 alleles), so only individuals with A1B1/A2B2 genotypes are able to develop into workers. $\mathrm{F}_{1}$ interlineage queens would produce four different types of gametes (A1B1, A1B2, A2B1 and A2B2 genotypes) of which only $25 \%$ would produce the right allelic composition for worker development when combined with gametes from males of a given lineage (either A1B2 or A2B1 genotypes). The third model proposed by Linksvayer et al. (2006) differs from the two previous models in that it involves interactions between the nuclear and cytoplasmic genomes. Individuals which have two haploid nuclear genomes that are compatible with their cytoplasmic genome (A1/A1c1 or A2/A2c2) would develop into queens, individuals with one haploid nuclear genome incompatible with the cytoplasmic genome (A1/A2c1 or A1/A2c2) would develop into workers and individuals with both haploid nuclear genomes being incompatible with the cytoplasmic genome (A1/A1c2 or A2/A2c1) would be inviable or sterile. An $\mathrm{F}_{1}$ interlineage queen would thus produce either $\mathrm{A} 1 \mathrm{c} 1$ and $\mathrm{A} 2 \mathrm{c} 1$ gametes or A1c2 and A2c2 gametes of which $50 \%$ could develop into workers when combined with gametes from males of either lineage (A1 or A2 genotypes). Overall, the observed 31\% (95\% CI: $24-39 \%$ ) viable backcross eggs most closely matches the two-locus model prediction. It should be noted, however, that we cannot exclude other causes for egg inviability, so this comparison is necessarily a weak test of the competing hypotheses. Moreover, the published formulations that we have considered represent only a small subset of the possible variants of each model. Indeed, a slight extension of the cyto-nuclear model with two nuclear loci interacting with the cytoplasm would also result in a prediction of $25 \%$ viable eggs.

The low viability of backcross progeny appeared to impose an increasingly severe cost on interlineage queen success during the course of colony growth. Interlineage queens produced $40 \%$ fewer workers than pure-lineage queens after 6 weeks of colony founding, but this difference increased to $50 \%$ after 24 weeks. Such productivity differences should strongly affect the probability of colony survival because the number of workers determines the competitive ability of incipient colonies and thus directly influences the probability of successful colony establishment (Gordon \& Kulig 1996). Although such a reduction in productivity should decrease the proportion of established colonies headed by interlineage queens relative to the proportion of interlineage queens that are produced, it does not totally explain the nearly complete lack of such colonies in the field. It is thus likely that there are additional as-yet unknown factors affecting the survival of colonies headed by interlineage queens.

Although interbreeding lineages are dependent on one another for worker production, they are also competitors for territory and resources. We found productivity differences between the two interbreeding lineages $\mathrm{H}_{1}$ and $\mathrm{H}_{2}$ that reflected their relative fecundities (Fig. 3b). After 
24 weeks, colonies headed by $\mathrm{H}_{2}-\mathrm{H}_{2}$ pure-lineage queens produced $16 \%$ more workers than colonies headed by $\mathrm{H}_{1-}$ $\mathrm{H}_{1}$ queens (Fig. 2). As noted in a previous study on the $\mathrm{J}_{1}$ and $\mathrm{J}_{2}$ lineages which also differ in productivity (Helms Cahan et al. 2004; Schwander et al. 2006), such initial productivity differences may translate into a long-term growth benefit for one of the two lineages and hence affect the relative abundances of the co-occurring lineages in the field. However, unlike the consistent patterns of $\mathrm{J}_{2}$ bias in the $\mathrm{J}_{1}-\mathrm{J}_{2}$ populations, we found that the relative frequencies of the $\mathrm{H}_{1}$ and $\mathrm{H}_{2}$ lineages in the field were not more often $\mathrm{H}_{2}$-biased than $\mathrm{H}_{1}$-biased (Table 1), suggesting that there may be other benefits to colonies headed by $\mathrm{H}_{1}-\mathrm{H}_{1}$ queens that counteract reduced fecundity in some environments.

In conclusion, this study demonstrates that genetic differentiation between dependent lineages in Pogonomyrmex remains high because of a very strict association of genotype and caste in the $\mathrm{J}_{1}-\mathrm{J}_{2}$ lineage pair and high fitness costs during colony founding for interlineage queens of the $\mathrm{F}_{1^{-}}$ $\mathrm{F}_{2}, \mathrm{G}_{1}-\mathrm{G}_{2}$ and $\mathrm{H}_{1}-\mathrm{H}_{2}$ lineage pairs. The differences between the two groups of lineage pairs in the production of interlineage queens are reflected in population genetic data that support the lack of historical gene flow between the $J_{1}$ and $\mathrm{J}_{2}$ lineages but suggest a low level of historical gene flow among the lineages of the three other lineage pairs. Importantly, the lack of current gene flow between interdependent lineages maintains the separation of genomes required to continually regenerate the interlineage worker genotype, and hence the genetic caste determination mechanism.

\section{Acknowledgements}

We would like to thank Jonas Cosendai and Taìsia Holdago for great help with laboratory work and especially ant care. Glennis Julian and volunteers from the Southwestern Research Station in Portal, Arizona provided much appreciated assistance with the sampling. This study was supported by several grants from the Swiss National Science Foundation to L.K. and by a grant of the Theodore Roosevelt Memorial fund to T.S.

\section{References}

Anderson KE, Gadau J, Mott BM et al. (2006a) Distribution and evolution of genetic caste determination in Pogonomyrmex seedharvester ants. Ecology, 87, 2171-2184.

Anderson KE, Hölldobler B, Fewell JH, Mott BM, Gadau J (2006b) Population-wide lineage frequencies predict genetic load in the seed-harvester ant Pogonomyrmex. Proceedings of the National Academy of Sciences, USA, 103, 13433-13438.

Barton NH, Hewitt GM (1985) Analysis of hybrid zones. Annual Review of Ecological Systematics, 16, 113-148.

Burke JM, Arnold ML (2001) Genetics and the fitness of hybrids. Annual Review of Genetics, 35, 31-52.

DeHeer CJ (2002) A comparison of the colony-founding potential of queens from single- and multiple-queen colonies of the fire ant Solenopsis invicta. Animal Behavior, 64, 655-661.
Fjerdingstad EJ, Keller L (2004) Relationships between phenotype, mating behavior, and fitness of queens in the ant Lasius niger. Evolution, 58, 1056-1063.

Gadau J, Strehl C-P, Oettler J, Hölldobler B (2003) Determinants of intracolonial relatedness in Pogonomyrmex rugosus (Hymenoptera; Formicidae): mating frequency and brood raids. Molecular Ecology, 12, 1931-1938.

Gordon DM, Kulig AW (1996) Founding, foraging, and fighting: colony size and the spatial distribution of harvester ant nests. Ecology, 77, 2393-2409.

Greig D, Borts RH, Louis EJ, Travisano M (2002) Epistasis and hybrid sterility in Saccharomyces. Proceedings of the Royal Society of London. Series B, Biological Sciences, 269, 1167-1171.

Helms Cahan S, Keller L (2003) Complex hybrid origin of genetic caste determination in harvester ants. Nature, 424, 306-309.

Helms Cahan S, Vinson SB (2003) Reproductive division of labor between hybrid and nonhybrid offspring in a fire ant hybrid zone. Evolution, 57, 1562-1570.

Helms Cahan S, Parker JD, Rissing SW et al. (2002) Extreme genetic differences between queens and workers in hybridizing Pogonomyrmex harvester ants. Proceedings of the Royal Society of London. Series B, Biological Sciences, 269, 1871-1877.

Helms Cahan S, Julian GE, Rissing SW, Schwander T, Parker JD, Keller L (2004) Loss of phenotypic plasticity generates genotypecaste association in harvester ants. Current Biology, 14, 22772282.

Helms Cahan S, Julian GE, Schwander T, Keller L (2006) Reproductive isolation between Pogonomyrmex rugosus and two lineages with genetic caste determination. Ecology, 87, 21602170.

Hotz H, Semlitsch RD, Gutman E, Guex G-D, Beerli P (1999) Spontaneous heterosis in larval life-history traits of hemiclonal frog hybrids. Evolution, 96, 2171-2176.

Hung ACF, Vinson SB (1977) Interspecific hybridization and caste specificity of protein in fire ant. Science, 196, 1458-1460.

Julian GE, Fewell JH, Gadau J, Johnson RA, Larrabee D (2002) Genetic determination of the queen caste in an ant hybrid zone. Proceedings of the National Academy of Sciences, USA, 99, 81578160.

Kulathinal R, Singh RS (1998) Cytological characterization of premeiotic versus postmeiotic defects producing hybrid male sterility among sibling species of the Drosophila melanogaster complex. Evolution, 52, 1067-1079.

Linksvayer TA, Wade MJ, Gordon DM (2006) Genetic caste determination in harvester ants: possible origin and maintenance by cyto-nuclear epistasis. Ecology, 87, 2185-2193.

Liu Z, Yamane S, Kojima J, Wang Q, Tanaka S (2001) Flexibility of first brood production in a claustral ant, Camponotus japonicus (Hymenoptera: Formicidae). Journal of Ethology, 19, 87-91.

Orr HA (2005) The genetic basis of reproductive isolation: insights from Drosophila. Proceedings National Academy of Sciences, USA, 102 (Suppl. 1), 6522-6526.

Schwander T, Helms Cahan S, Keller L (2006) Genetic caste determination in Pogonomyrmex harvester ants imposes costs during colony founding. Journal of Evolutionary Biology, 19, 402-409.

Schwander T, Helms Cahan S, Keller L (2007) Characterization and distribution of Pogonomyrmex harvester ant lineages with genetic caste determination. Molecular Ecology, 16, 367387.

Umphrey GJ (2006) Sperm parasitism in ants: selection for interspecific mating and hybridization. Ecology, 87, 2148-2159. 
Umphrey GJ, Danzmann RG (1998) Electrophoretic evidence for hybridization in the ant genus Acanthomyops (Hymenoptera, Formicidae). Biochemical Systematics and Ecology, 26, 431-440.

Volny VP, Gordon DM (2002a) Genetic basis for queen-worker dimorphism in a social insect. Proceedings of the National Academy of Sciences, USA, 99, 6108-6111.

Volny VP, Gordon DM (2002b) Characterization of polymorphic microsatellite loci in the red harvester ant, Pogonomyrmex barbatus. Molecular Ecological Notes, 2, 302-303.

Wagner D, Gordon DM (1999) Colony age, neighborhood density and reproductive potential in harvester ants. Oecologia, 119, 175-182.
Wiernasz DC, Cole BJ (2003) Queen size mediates queen survival and colony fitness in harvester ants. Evolution, 57, 2179-2183.

This work is part of T. Schwander's PhD thesis on the evolution and consequences of genetic caste determination in Pogonomyrmex harvester ants. S. Helms Cahan's research focuses on the consequences of sociality on the evolution of individual, population, and species characteristics. L. Keller works on various aspects of evolutionary ecology and social behaviour in ants. 